\title{
Oxidative Stress Induction By Pesticides May Cause Lung Cancer Incidence
}

\author{
Gholamreza Asadikaram \\ Kerman University of Medical Sciences \\ Hossein Pourghdamyari \\ Kerman University of Medical Sciences \\ Moslem Abolhassani ( $\triangle$ moslemabolhassani@gmail.com ) \\ Kerman University of Medical Sciences \\ Mojtaba Abbasi-Jorjandi \\ Kerman University of Medical Sciences \\ Sanaz Faramarz \\ Kerman University of Medical Sciences \\ Fatemeh Yousefi \\ Kerman University of Medical Sciences \\ Fouzieh Salimi \\ Kerman University of Medical Sciences \\ Reza Malekpour Afshar \\ Kerman University of Medical Sciences \\ Parisa Asadikaram \\ Shiraz University of Medical Sciences \\ Mohsen Shafiepour \\ Kerman University of Medical Sciences
}

Research Article

Keywords: Acetylcholinesterase, Lung Cancer, Organochlorine, Organophosphorous Oxidative stress

Posted Date: January 3rd, 2022

DOI: https://doi.org/10.21203/rs.3.rs-1204945/v1

License: (c) (7) This work is licensed under a Creative Commons Attribution 4.0 International License. Read Full License 


\section{Abstract \\ Background and aims:}

Pesticides are nowadays known as one of the most important causes of human disorders worldwide. The aim of the present study was to investigate the role of organochlorine pesticides (OCPs) and organophosphorus pesticides (OPPs) in the development of lung cancer.

\section{Methods}

We determined the levels of seven derived OCP residues ( $\mathrm{a}-\mathrm{HCH}, \beta-\mathrm{HCH}, \mathrm{\gamma}-\mathrm{HCH}, 2,4 \mathrm{DDT}, 4,4 \mathrm{DDT}, 2,4 \mathrm{DDE}$, and 4,4 DDE) and enzymatic antioxidant biomarkers including paraoxonase-1 (PON-1), erythrocyte's acetylcholinesterase (AChE), glutathione peroxidase (GPx), superoxide dismutase (SOD), catalase (CAT), and non-enzymatic antioxidant biomarkers including total antioxidant capacity (TAC), protein carbonyl (PC), malondialdehyde (MDA), and nitric oxide (NO) in the blood samples of 51 lung cancer patients and 51 healthy subjects as controls. Furthermore, the effects of OPP exposure on the development of lung cancer and oxidative stress (OS) are indirectly assessed by measuring AChE and PON-1 enzyme activities.

\section{Results}

The average values of all the measured OCPs were significantly higher in lung cancer patients when compared with healthy control subjects. AChE, PON-1, GPX, and CAT activity levels as well as the amounts of PC, MDA, and NO were higher in patients with lung cancer than in the control subjects, while TAC values were lower in the patients. Moreover, our data showed a significant association between OCP concentrations and OS parameters.

\section{Conclusion}

The results suggest that OCPs and OPPs may have a role in lung cancer incidence in southeastern Iran, and at least one of the mechanisms by which OCPs and OPPs may contribute to increasing the development of lung cancer in the studied area is through OS generation.

\section{Introduction}

In the world's population, one of the most common cancers is lung cancer, which is the prominent reason for mortality (Basumallik \& Agarwal, 2019). It has even been reported that lung cancer in comparison to breast cancer may cause more deaths in women (Siddiqui \& Siddiqui, 2019; Siegel et al., 2016). Based on yearly epidemiological studies, over 200,000 new cases of lung cancer were recently diagnosed in the United States (Basumallik \& Agarwal, 2019; Rybarczyk-Kasiuchnicz \& Ramlau, 2018). Indeed, the number of patients with lung cancer will increase exponentially without urgent action. In other words, this disease is transforming into a major health problem (Mao et al., 2016). Despite recent advances in cancer diagnosis and treatment (Mardani et al., 2019; Mirzaei et al., 2018), this illness is still one of the major challenges in medical science (Tahmasebi-Birgani et al., 2019). Thus, to combat cancer as a serious disease, the best strategy is control and prevention (Cramb et al., 2015). Notably, the etiology and pathophysiology of lung cancer are not fully elucidated. Therefore, identifying risk factors for lung cancer is critical in preventing and controlling the disease. However, in recent years, accumulated evidence has shown that environmental and lifestyle factors contribute to the development of lung cancer. These factors include tobacco smoking (Miranda-Filho et al., 2019), family history (Cannon-Albright et al., 2019), sex (Boice Jr et al., 2019), obesity (Yang et al., 2013), alcohol (Wei et al., 2018), and environmental chemicals (Luo et al., 2011).

Moreover, it has been proven that there is a direct relationship between exposure to pesticides and cancer. In this regard, investigators have found that pesticides, as environmental chemicals, increase the vulnerability to cancer. Pesticides have been widely used in various fields, especially in agriculture to eliminate insects, weeds, and fungi in order to improve agricultural products in terms of quality and quantity (Jayaraj et al., 2016).

A growing interest has been recently attracted to the main groups of pesticides including organochlorines (OCPs) and organophosphates (OPPs) as risk factors for cancer (Martin et al., 2018; Peppers, 2019). Our previous studies have shown that OCPs and OPPs, as new environmental risk factors, can predispose individuals to cancers such as breast (Paydar et al., 2019), bladder (Mortazavi et al., 2019b), and colorectal cancer (Abolhassani et al., 2019).

DDT and its derivatives, hexachlorocyclohexane $(\mathrm{HCH})$ and chlorinated cyclodiene, are three members of the OCP family that have a long half-life and are hard to break down in the environment and foods (Paydar et al., 2019; Pirsaheb et al., 2015). Due to their high accumulation and persistence in the body, the use of OCP family pesticides has been banned since the 1980s (He et al., 2017; Paydar et al., 2019). Moreover, it has been proven that OCP accumulation in the animal and human body for a long time can induce oxidative stress (OS), which leads to oxidant-antioxidant imbalance as well as disruption of cellular signaling (Bhardwaj et al., 2018; Singh et al., 2016). Previous studies have shown that OS is closely related to numerous diseases such as cancer, cardiovascular diseases, and diabetes (Abolhassani et al., 2019; Lima et al., 2019; Moohebati et al., 2011).

OPPs are volatile pesticides that contain phosphorus in their structure (Deng et al., 2015). A remarkable number of studies have demonstrated that OPPs are able to decrease acetylcholinesterase (AChE) activity through binding to the enzyme active site and phosphorylating it. Therefore, OPPs can exert pernicious and pervasive influences on the cholinergic system (Rui et al., 2018; Valdez et al., 2019). Due to the volatility of these compounds, it is difficult to measure them directly. Accordingly, the evaluation of AChE activity in red blood cells (RBCs) is broadly used to assess exposure to OPPs and OCPs (Majidi et al., 2018).

Since Kerman Province is the leading agricultural hub of southeastern Iran, there is an increasing concern about myriad potential biological activities and the side effects of these extensively used pesticides (Hadian et al., 2019; Rezaeigolestani \& Hashemi, 2018). Moreover, in previous studies, we have shown a high

Page $2 / 20$ 
degree of contamination by OCPs and OPPs in cancer patients (Abolhassani et al., 2019; Mortazavi et al., 2019b; Paydar et al., 2019) in Kerman Province.

The aim of this study was to evaluate the serum OCP levels (including $\alpha-\mathrm{HCH}, \beta-\mathrm{HCH}, \mathrm{y}-\mathrm{HCH}, 2,4 \mathrm{DDE}, 4,4 \mathrm{DDE}, 2,4 \mathrm{DDT}$, and 4,4 DDT) in lung cancer and healthy subjects in southeastern Iran to assess whether lung cancer risk can be related to serum OCP and OPP levels. To this end, we also investigated the effects of OPPs and OCPs on OS status in lung cancer and healthy subjects via the evaluation and comparison of non-enzymatic antioxidants, including nitric oxide (NO), malondialdehyde (MDA), and protein carbonyl (PC), and antioxidant enzyme activities, including catalase (CAT), superoxide dismutase (SOD), and glutathione peroxidase (GPx) activities, along with the activity of paraoxonase-1 (PON-1) and AChE in the lung cancer patients and control subjects.

\section{Materials And Methods}

\section{Samples and data collection}

The current case-control study was conducted on 51 patients newly diagnosed with lung cancer in Afzalipoor Hospital of Kerman University of Medical Sciences, Kerman, Iran (July 2017-May 2019). The control group included 51 healthy individuals with no evidence of any disease. The diagnosis of lung cancer was established by a lung imaging fluorescence endoscope device and whole-body positron emission tomographic imaging.

All of the participants (male and female) in this study were newly diagnosed. In addition, none of them had a history of chronic and autoimmune diseases, alcohol consumption, or hormone therapy, and they were not using any vitamin and iron supplementations. All participants signed a written consent form and the patient's refusal to participate in the study was one of the exclusion criteria. Moreover, patients who had a history of exposure to ionizing radiation or those who were consuming vitamin and iron supplementations were excluded from the study.

The participants in the control group had no history of cancer or acute and chronic diseases based on clinical records, lung imaging fluorescence endoscopy, and whole-body positron emission tomographic imaging. Moreover, they were not taking antioxidant supplements, smoking, or consuming alcohol. In the present study, patients were matched to controls based on smoking. The Declaration of Helsinki was used as the cornerstone document for instructing the ethical standards to physicians and participants. The research was approved by the ethics board of Kerman University of Medical Sciences (Code No: IR.KMU.REC.1398.335).

A questionnaire was used to collect the demographic data. First, $10 \mathrm{~mL}$ of venous blood was collected from the participants. Then $0.5 \mathrm{~mL}$ of the blood sample was transferred to EDTA tubes (to measure AChE) and the remnants were transferred to tubes without anti-coagulation substances. Next, the serum was separated via centrifugation (10 $\mathrm{min}$ at $3000 \mathrm{rpm})$. The serum samples were transmitted to a sterile sample tube holder and were kept at $-70^{\circ} \mathrm{C}$ until further analysis.

\section{Biochemical parameters}

Total cholesterol (TC), triglyceride (TG), and high-density lipoprotein-cholesterol (HDL-C) serum levels were measured by standard kits (Pars Azmoon, Tehran, Iran) using an autoanalyzer (Selectra-XL, Vital Science; Netherlands) in a standard laboratory setting. The levels of low-density lipoprotein-cholesterol (LDL-C) were determined by the Friedewald equation (Friedewald et al., 1972).

\section{Measurement of erythrocyte AChE activity}

Hyamine 1622, acetylcholine iodide, and 5, 5-dithio-bis-2-nitrobenzoic acid (DTNB) were obtained from Sigma (Saint Louis, MO, USA). Ellman's modified procedure was used to calculate AChE activity in the erythrocytes of all samples (Worek et al., 1999) as described elsewhere (Abolhassani et al., 2019; Mortazavi et al., 2019a; Paydar et al., 2018). First, $6 \mathrm{~mL}$ of distilled water was used to dilute $100 \mu \mathrm{L}$ of erythrocytes which were washed by normal saline. Next, the reaction buffer (containing $0.28 \mathrm{mmol}$ DTNB, $3.2 \mathrm{mmol}$ acetylcholine iodide, and $20 \mu \mathrm{M}$ quinidine sulfate) was used to incubate $100 \mu \mathrm{L}$ of the diluted sample at $37^{\circ} \mathrm{C}$ for $10 \mathrm{~min}$. Finally, to stop the reaction, $1 \mathrm{~mL}$ of Hyamine 1622 was added to the solution. 5-thio-2-nitrobenzoic acid (with maximum absorbance at $440 \mathrm{~nm}$ ) was the product of the reaction between thiocholine and the chromophore DTNB (Worek et al., 1999).

\section{Assessment of the arylesterase activity of PON-1}

Phenylacetate (a substrate of arylesterase activity) was purchased from Sigma Chemical Co. (Saint Louis, MO, USA). Serum arylesterase activity of PON-1 was calculated based on the procedure suggested by Bobin-Dubigeon et al. (2012) as described elsewhere (Abolhassani et al., 2019; Mortazavi et al., 2019b; Paydar et al., 2018). First, the rate of phenylacetate hydrolysis was assessed in order to determine arylesterase activity. Afterward, the substrate (2 mM phenylacetate), $2 \mathrm{mM} \mathrm{CaCl}_{2}$ (Merck, Darmstadt, Germany), and $10 \mu \mathrm{L}$ of serum in $100 \mathrm{mM}$ Tris- $\mathrm{HCl}$ (Merck, Darmstadt, Germany) ( $\left.\mathrm{pH}=8.0\right)$ were used to prepare the reaction mixture. The incubation process of the mixture was performed for 3 min at $37^{\circ} \mathrm{C}$. Finally, the level of phenylacetate hydrolysis was evaluated at $270 \mathrm{~nm}$.

\section{Measurement of MDA}

MDA is a compound that can be evaluated as a lipid peroxidation index. The thiobarbituric acid (TBA) assay is used for evaluating this substance as described elsewhere (Abolhassani et al., 2019; Mortazavi et al., 2019b; Paydar et al., 2018). In the presence of the trichloroacetic acid (TCA)-TBA-hydrochloric acid (HCL) reagent, MDA reacts with TBA and produces a pink color. To perform the assay, $200 \mu \mathrm{L}$ of the solution buffer was added to $100 \mu \mathrm{L}$ of serum and the absorbance was measured at $535 \mathrm{~nm}$ (Buege \& Aust, 1978).

\section{Total antioxidant capacity (TAC) assay}

The procedure suggested by Benzie and Strain (1996) was used to evaluate the ferric-reducing ability of plasma (FRAP) (Benzie \& Strain, 1996). Plasma is capable of reducing ferric tripyridyltriazine (Fe III-TPTZ) complex to an intense blue-colored ferrous (Fe II) form at low pH. The maximum absorbance of this 
complex is at $593 \mathrm{~nm}$ and the blue color intensity is relative to the antioxidant capacity of the sample as explained in prior research (Abolhassani et al., 2019; Mortazavi et al., 2019a; Paydar et al., 2018). Briefly, $70 \mu \mathrm{L}$ of the FRAP reagent and $5 \mu \mathrm{L}$ of serum were mixed. Blank was distilled water; the mixture was incubated at $37^{\circ} \mathrm{C}$ for $5 \mathrm{~min}$, and the absorbance was determined at $593 \mathrm{~nm}$. The FRAP values are expressed in micromolar $(\mu \mathrm{M})$.

\section{SOD activity measurement}

The total SOD activity was measured according to the Randox kit protocol (UK; Cat NO.RS504). SOD functions as a catalyst in the dismutation of the superoxide radical $\left(\mathrm{O}_{2}^{-}\right)$into hydrogen peroxide $\left(\mathrm{H}_{2} \mathrm{O}_{2}\right)$ and elemental oxygen $\left(\mathrm{O}_{2}\right)$. In the Randox assay kit, superoxide ions $\left(\mathrm{O}_{2}{ }^{-}\right)$, which are produced either by xanthine oxidase (XOD) or through the conversion of xanthine to uric acid and hydrogen peroxide, are responsible for converting nitroblue tetrazolium (NBT) to NBT-diformazan. Briefly, $250 \mu \mathrm{L}$ of the work solution was added to $10 \mu \mathrm{L}$ tNBT-diformazan, which absorbs light at $560 \mathrm{~nm}$. SOD lowers the speed of NBT-diformazan formation by reducing the concentration of superoxide ions. SOD activity is measured by calculating the level of reduction that happens in the presence of NBT-diformazan in an experimental sample.

\section{Determination of GPx3 activity}

The GPx assay was conducted via the method described by Paglia and Valentine (1967) using the Randox kit (UK; Cat NO.SD125). The Randox GPx assay kit measures GPx activity indirectly by a coupled reaction with glutathione reductase (GR). GR is an enzyme responsible for regenerating the reduced form of oxidized glutathione (GSSG), which is generated when GPx produces an organic peroxide. The absorbance decreases at $340 \mathrm{~nm}$ (A340) when NADPH oxidizes to NADP+, which is a spectrophotometric means for measuring the activity of the GPx enzyme. Briefly, $10 \mu \mathrm{L}$ of serum was added to the work solution that was included in the kit.

\section{Determination of CAT activity}

CAT activity was determined according to the method described by Sinha (Sinha, 1972) with minor modification. Briefly, the reaction mixture, which contained phosphate buffer $(50 \mathrm{mM}$; $\mathrm{pH} 7.4), 30 \mathrm{mM} \mathrm{H}_{2} \mathrm{O}_{2}$, and the dichromate/acetic acid solution ( $5 \%$ aqueous solution of potassium dichromate in distilled water + $150 \mathrm{~mL}$ of glacial (98-100\%) acetic acid), was heated for $10 \mathrm{~min}$ in a boiling water bath in separate tubes for each sample. Then $\mathrm{H}_{2} \mathrm{O}_{2}$ was added to $100 \mu \mathrm{L}$ of serum. After that, dichromate/acetic was added. The absorbance of samples was measured at $570 \mathrm{~nm}$ by a spectrophotometer.

\section{PC assay}

The measurement of PCs following their covalent reaction with 2,4-dinitrophenylhydrazine (DNPH) was pioneered by Levine et al. (1990). Since PCs react with DNPH, this method is a suitable approach for their identification. This procedure involves treating proteins that are oxidatively modified (40.5 mg of protein) with $10 \mathrm{mM}$ DNPH for $1 \mathrm{~h}$. Briefly, $400 \mu \mathrm{L}$ of DNPH was added to $100 \mu \mathrm{L}$ of the serum sample. Then proteins were precipitated by adding $20 \%$ TCA to the solution. After that, precipitates were washed three times with ethanol-ethyl acetate (1:1), and the final precipitate was dissolved in $6 \mathrm{M}$ guanidine. Finally, the absorbance of the 2,4-dinitrophenyl (DNP) hydrazones was measured at $370 \mathrm{~nm}$.

\section{The biological activity of nitrite and nitrate}

The Griess method was used to measure the level of NO in serum. Since deproteinization is a crucial step in this measurement process, serum deproteinizing was initially performed using $\mathrm{ZnSO}_{4}$ in the presence of $0.3 \mathrm{M} \mathrm{NaOH}$. Then vanadium (III) chloride $\left(\mathrm{VaCl}_{3}\right)$ (which converts nitrate into nitrite) and the Griess reagent ( $2 \%$ sulphanilamide in $5 \%$ phosphoric acid and $0.1 \% \mathrm{~N}$-(1-naphthyl) ethylenediamine dihydrochloride (NEDD) in deionized water) were mixed with the deproteinated serum, and the mixture was incubated at $37^{\circ} \mathrm{C}$ for $30 \mathrm{~min}$. Finally, optical density (OD) measurement was performed at $540 \mathrm{~nm}$ (Yucel et al., 2012).

\section{Measurement of OCPs}

The standards of OCPs, including a-HCH, $\beta-\mathrm{HCH}, \mathrm{\gamma}-\mathrm{HCH}, 2,4 \mathrm{DDT}, 4,4 \mathrm{DDT}, 2,4 \mathrm{DDE}$, and 4,4 DDE, and the internal standard (4,4-dichlorobenzophenone, DBP) were obtained from Ehrenstorfer Company (Germany). n-hexane, anhydrous sodium sulfate, and ethyl acetate were purchased from Merck (Germany), and sulphuric acid was obtained from Scharlab (Spain).

A gas chromatographic (GC) analyzer (Agilent 7890A, USA), which was coupled to a flame ionization detector (FID), was used to measure and detect the residues of serum OCPs in all the participants. Zumbado et al. (2005) suggested a modified method for identifying OCP residues as described elsewhere (Abolhassani et al., 2019; Mortazavi et al., 2019b; Paydar et al., 2019; Paydar et al., 2018). First, the internal standard (DBP) was mixed with $0.5 \mathrm{~mL}$ of serum. The extraction of samples was repeated twice with $2 \mathrm{~mL}$ of hexane. Then, $200 \mu \mathrm{L}$ of concentrated sulphuric acid was added to combined extracts in order to separate the organic part. Next, $100 \mathrm{mg}$ of anhydrous sodium sulfate was used to dehydrate this organic part, and centrifugation was performed at $3000 \mathrm{~g}$. After that, the transferred organic layer was completely concentrated at room temperature. Eventually, $100 \mu \mathrm{L}$ of ethyl acetate was added to each sample in order to dissolve the extracted OCPs. GC-FID and capillary columns (HP-5) are reported as analytical methods for the identification of OCPs. The retention time (used for qualitative analysis), peak area (used for quantitative analysis), and the internal standard method were utilized to calculate the serum levels of OCPs. Therefore, a set of OCP standard solutions with certain concentrations $(0.78,1.56,3.12,6.25,12.5,25,50,100,200$, and $400 \mu \mathrm{g} / \mathrm{mL}) \mathrm{was}$ prepared and then equal levels of DBP $(100 \mu \mathrm{g} / \mathrm{mL})$ were added to each OCP standard solution. Afterward, the peak areas of OCP standards and DBP were calculated, and calibration curves were obtained for each OCP compound, displaying the ratio of the peak area of the OCP standard to that of the internal standard versus the concentration. The peak areas of the OCPs and the internal standard for unknown samples were calculated and the ratio of the peak area was reported. In the final step, the OCP standard curves were used to determine OCP concentrations. The analytical limit of detection (LOD) was estimated to be $0.9 \mathrm{ng} / \mathrm{mL}$ for a$\mathrm{HCH}, 0.56 \mathrm{ng} / \mathrm{mL}$ for $\beta-\mathrm{HCH}, 0.31 \mathrm{ng} / \mathrm{mL}$ for $\mathrm{y}-\mathrm{HCH}, 0.59 \mathrm{ng} / \mathrm{mL}$ for 2,4 DDE, $0.68 \mathrm{ng} / \mathrm{mL}$ for 4,4 DDE, $0.29 \mathrm{ng} / \mathrm{mL}$ for 2,4 DDT, and 0.58 ng/mL for 4,4 DDT.

\section{Quality assurance and quality control (QA/QC)}


QA/QC was maintained to ensure the accurate quantification of OCPs. All the samples were analyzed in triplicate, as well as field blanks and equipment blanks. All the reported analytical results are the average of three values so that method performance can be evaluated. In this regard, a set of pesticide standard solutions with known concentrations $(0.05,0.1,0.5,0.75,1,2,4,8,16,25,50,100 \mu \mathrm{g} / \mathrm{L})$ were spiked in the pooled sample, and the calibration curves were obtained. Procedure blanks were prepared using ethyl acetate and routinely analyzed to check for inlet, column, and detector contamination during extraction and injection processes, examine the cross-contamination, and monitor the background contamination of the instrument.

\section{Statistical analysis}

Mean \pm standard error of the mean (SEM) are used to represent all continuous variable data and numbers (percentages) are used to represent categorical variables. The Kolmogorov-Smirnov test was used to assess data distribution. One-way ANOVA or Kruskal-Wallis with post-hoc Tukey and Mann-Whitney U tests, as well as the chi-square test, were used to analyze the differences between the groups. Pearson and Spearman's rho correlation coefficients were employed to manifest the correlations between continuous variables. In the present study, linear regression was carried out to determine the effects of OCPs (as independent variables) on OS development (as a dependent variable). The associations between continuous OCP concentrations and OS parameters in all plasma samples were explored using multivariable linear regression models. The associations between lung cancer development and OCPs were evaluated by the continuous logistic regression model based on adjustments for body mass index (BMI) and total lipids. The present study assessed exposure as a categorical variable, by classifying each OCP as quartiles of exposure in the study population. For each OCP, we determined the odds ratios (OR) for lung cancer, comparing each quartile with quartile 1. SPSS software version 22.0 for Windows (SPSS Inc., Chicago, IL) was applied for the statistical analyses. Pvalues $<0.05$ were considered statistically significant. All measurements for the studied pesticides were detected above the LOD. The measurement of LOD was based on the standard deviation of the regression line and the slope of the calibration curve. Moreover, we used both wet-weight concentrations adjusted for serum cholesterol and TG and lipid-standardized concentrations by dividing wet-weight concentrations by total lipids. Total lipids were calculated using the following formula: Total lipids $(\mathrm{mg} / \mathrm{dL})=2.27 \times$ total cholesterol $+\mathrm{TG}+62.3$ (Phillips et al., 1989). In addition to the individual OCPs, we calculated the molar sums (mmol/L) of DDT and its metabolites (2,4 DDT and 4,4 DDT), PHCHs ( $\mathrm{a}-\mathrm{HCH}, \beta-\mathrm{HCH}, \mathrm{Y}-\mathrm{HCH})$, and DDE (2,4 DDE and 4,4 DDE) using a previously reported method (Kobrosly et al., 2014).

\section{Results}

\section{Demographic variables and clinical characteristics}

The current case-control study was performed at Afzalipoor Hospital, Kerman, Iran, from February 2018 to September 2019. The study included 51 patients with pathologically confirmed lung cancer and 51 healthy individuals as the case and control groups, respectively. Notably, the two groups were matched in terms of age and gender. The mean age of the participants was $65.50 \pm 15.01$ years for the lung cancer group and $63.15 \pm 9.60$ years for the control group, which did not differ significantly. In the lung cancer group, there were 38 male subjects (74.5\%) and 13 female subjects (25.5\%). There were 39 male subjects (76.5\%) and 12 female subjects (23.5\%) in the control group. Sociodemographic variables and clinical features of the study participants are shown in Table 1. About $49 \%$ of the participants were current smokers; $51.02 \%$ ( 25 out of 51 ) of the lung cancer patients and $48.98 \%$ ( 24 out of 51 ) of the control patients were currently smoking. A total of 58 individuals were active in the agricultural sector (farming), including 35 (60.34\%) subjects with lung cancer and 23 (39.66\%) subjects in the control group. As shown in Table 1, BMI $(P=0.001)$, education $(P=0.04)$, farming $(P=0.016)$, living region $(P=0.028), T G$ levels $(P=0.022)$, and cholesterol levels $(P=0.012)$ in patients with lung cancer indicated significant differences compared to the control group. Other sociodemographic variables and clinical characteristics, such as smoking, HDL-C, LDL-C, and total protein, did not show any significant differences between patients with lung cancer and the control group. In addition, clinical and sociodemographic parameters were separately compared between men and women in the two groups (Table 1). 
Table 1

Comparison of demographic and other characteristics of participant between lung cancer and control subjects.

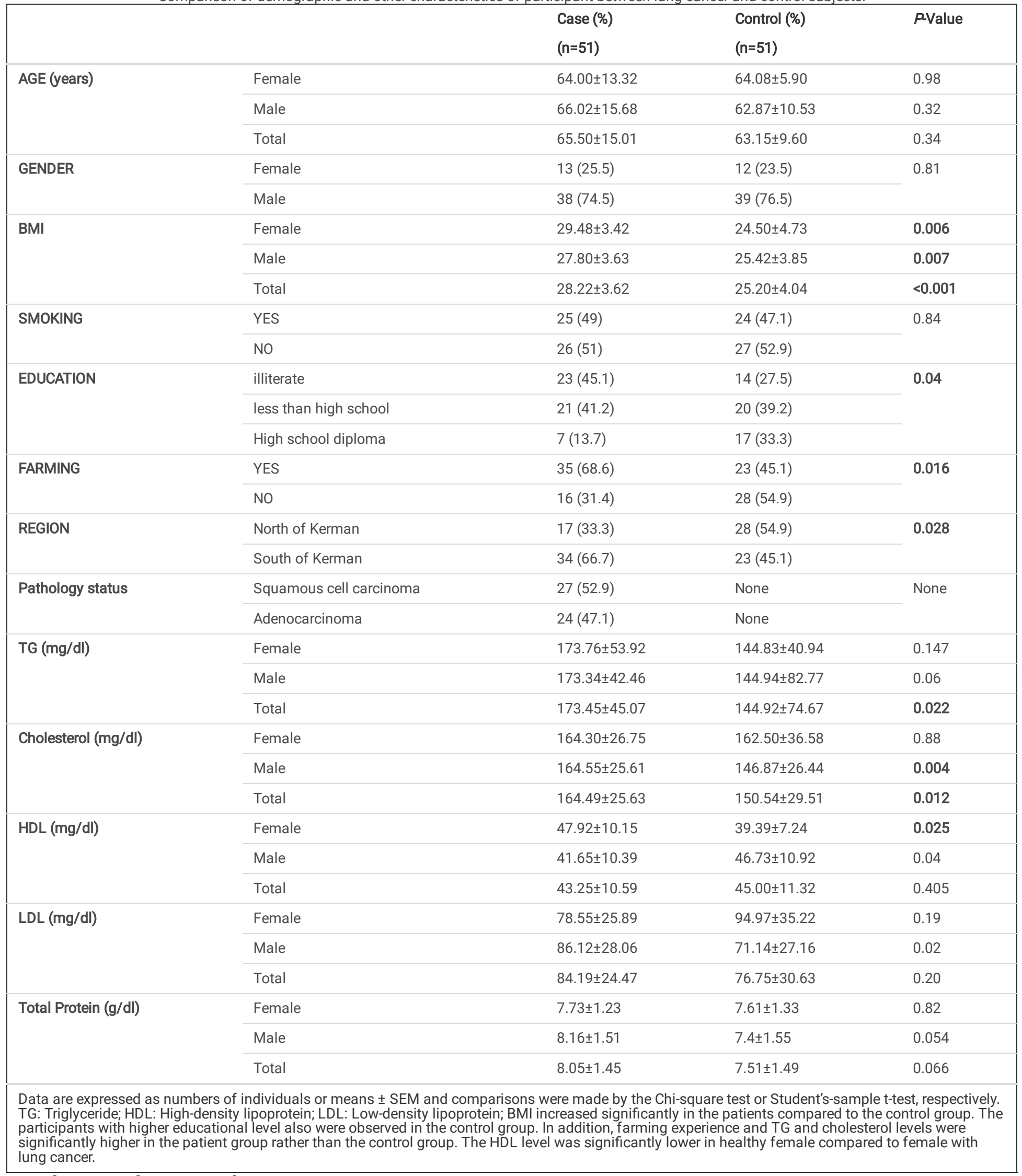

\section{Oxidant and antioxidant parameters}

To evaluate oxidant and antioxidant conditions, MDA, TAC, NO, and CP levels as well as the activity of SOD, GPx, AChE, PON-1, and CAT were assessed in patients with lung cancer and the healthy control group. As shown in Figure 1, the mean SOD activity level was not significantly different between the two groups $(P=0.23)$. However, according to this figure, AChE, PON-1, CAT, and GPx activity levels in patients with lung cancer were significantly lower than those 
in the control subjects $(P<0.001, P<0.001, P=0.001$, and $P<0.005$, respectively). Similarly, the results showed a significant decrease in TAC values in patients with lung cancer compared to healthy control subjects $(P<0.001)$. Moreover, Figure 1 shows the comparison of oxidant and antioxidant parameters between men and women in the two groups separately. As observed, the mean GPx activity level was not significantly different between the female

participants of the two groups $(P=0.28)$. In addition, Figure 1 indicates that the mean $P C, M D A$, and NO concentrations were statistically higher in lung cancer patients compared to the healthy controls $(P<0.001$ for the three comparisons).

OCPs

Gas chromatography was used to measure the level of seven OCP derivatives including 2,4 DDE, 2,4 DDT, 4,4 DDT, 4,4 DDE, a-HCH, $\beta$-HCH, and $\gamma-\mathrm{HCH}$ in patients with lung cancer and healthy controls. As shown in Table 2, the mean levels of all OCPs were significantly higher in patients with lung cancer in comparison with healthy control subjects ( $P<0.001$ for all comparisons). Table 2 also compares the summation of HCH, DDE, and DDT subtypes as well as the summation of all OCP concentrations between men, women, and all the subjects of both groups separately. 
Table 2

The OCPs ( $\mathrm{ng} / \mathrm{ml}$ and $\mathrm{ng} / \mathrm{g}$ lipid) levels in lung cancer and controls.

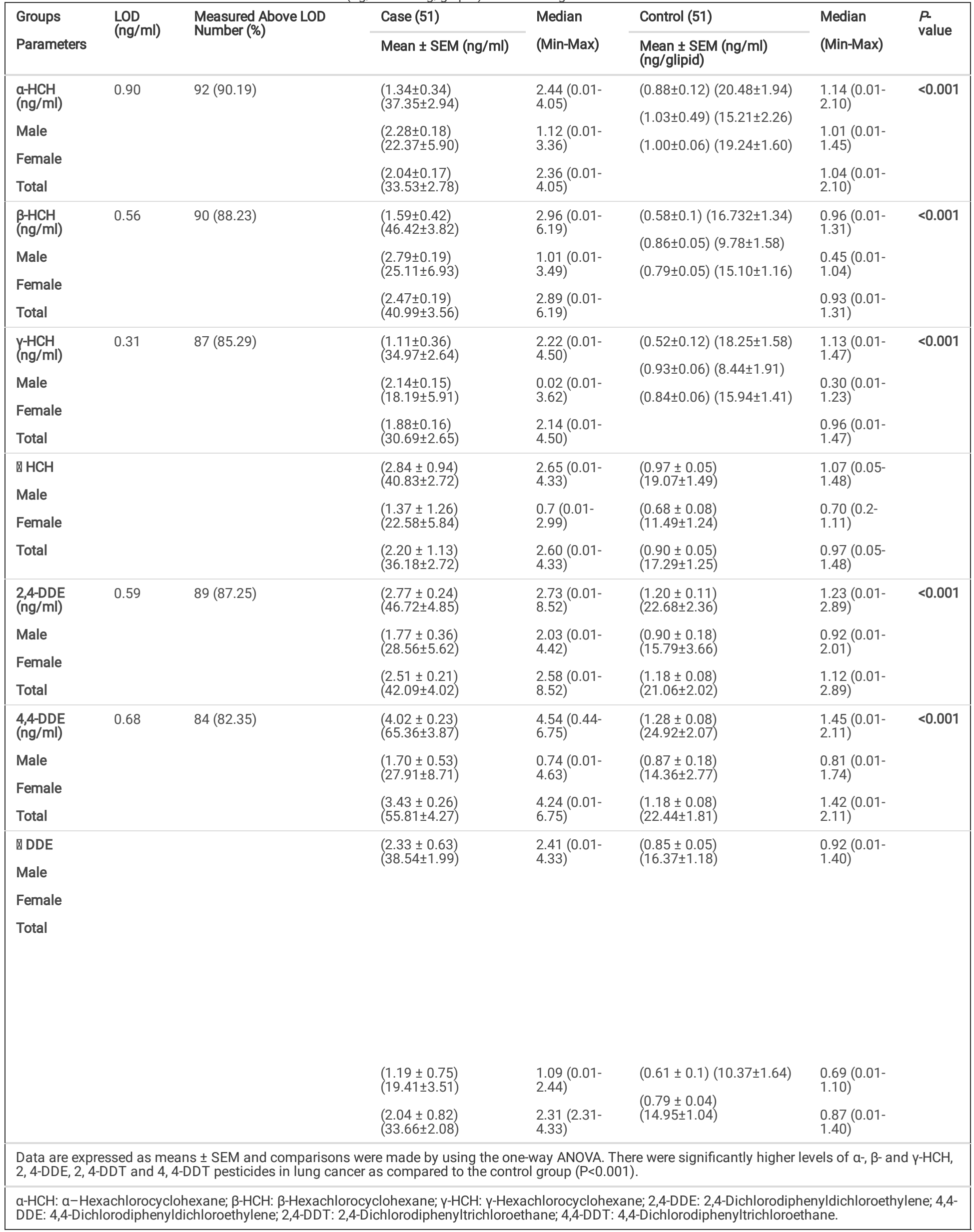




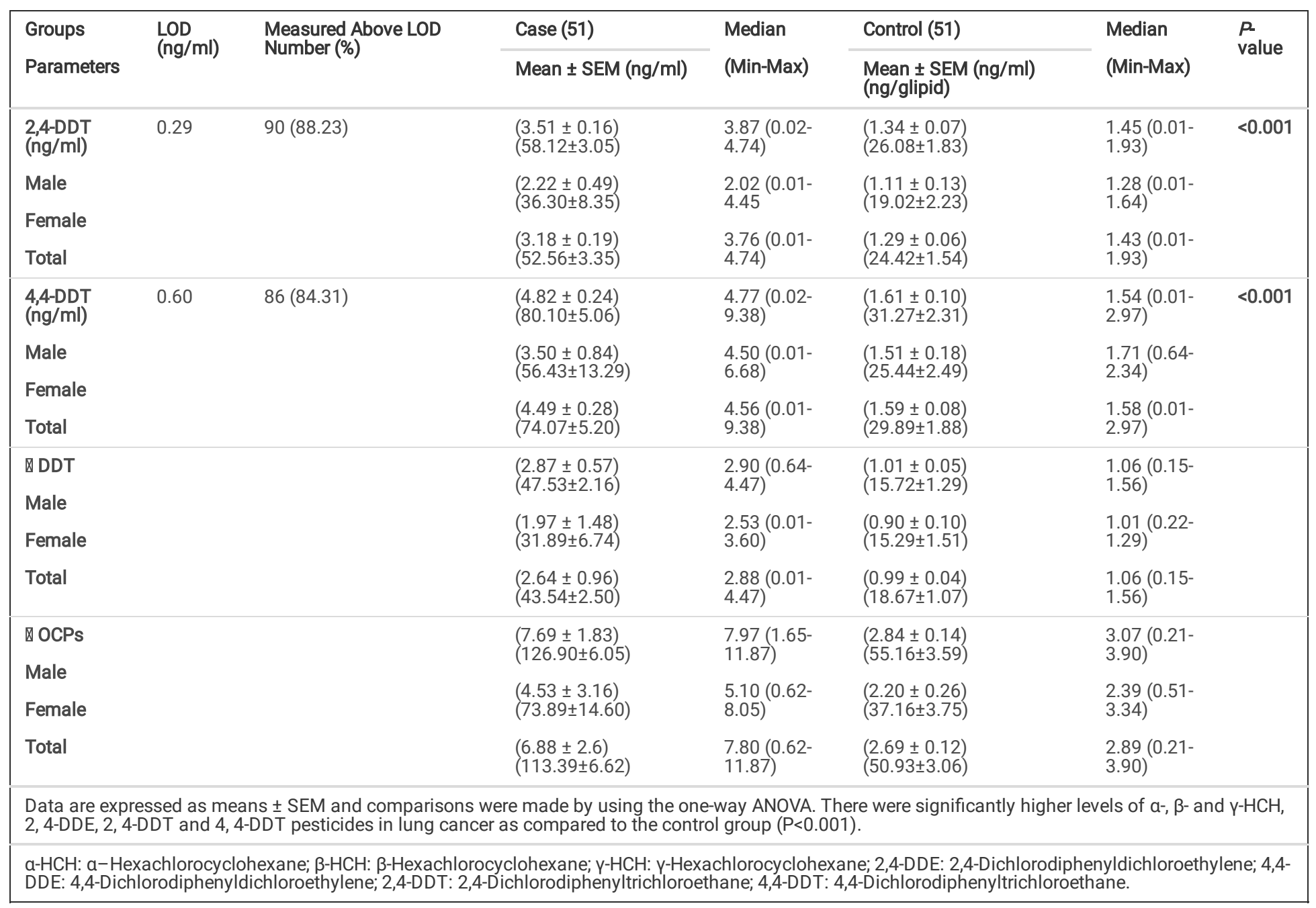

The scatter dot plot was employed to more clearly depict the distribution of OCPs in patients with lung cancer and healthy control subjects (Figure 2). It is apparent from this plot that the distribution of all the OCPs in patients with lung cancer was significantly higher than the healthy controls.

\section{Correlation analysis}

Spearman correlation was applied to evaluate the association of the sociodemographic variables and oxidant and antioxidant parameters with OCP levels in patients with lung cancer (Table 3 and Table 4). 
Table 3

Overall correlation among studied parameters of OCPs exposed subjects.

\begin{tabular}{|c|c|c|c|c|c|c|c|c|c|c|c|c|c|c|c|}
\hline & AChE & PON1 & MDA & TAC & NO & PC & SOD3 & GPx3 & CAT & Age & BMI & $\mathrm{a}-\mathrm{HCH}$ & $\beta-\mathrm{HCH}$ & $\mathrm{Y}-\mathrm{HCH}$ & $\begin{array}{l}2 \\
\mathrm{D}\end{array}$ \\
\hline AChE & 1.0 & 0.085 & -0.222 & 0.217 & -0.280 * & -0.165 & $-0.285^{*}$ & 0.220 & 0.254 & 0.041 & $-0.346 *$ & -0.276 & -0.204 & $-0.283^{*}$ & $-\mathrm{C}$ \\
\hline PON1 & - & 1.0 & -0.202 & 0.164 & -0.168 & -0.185 & 0.088 & $0.281 *$ & $0.305^{*}$ & 0.116 & -0.202 & -0.181 & -0.320 * & $-0.348^{*}$ & $-c$ \\
\hline MDA & - & - & 1.0 & 0.135 & 0.230 & $0.287^{*}$ & 0.105 & -0.246 & $-0.314^{*}$ & 0.083 & $0.297 *$ & 0.088 & 0.268 & 0.095 & 0 \\
\hline TAC & - & - & - & 1.0 & .004 & -0.164 & -0.026 & 0.223 & $0.288 *$ & $0.296 *$ & -0.142 & -0.310 * & $-0.394^{* *}$ & $-0.412^{* *}$ & $-\mathrm{C}$ \\
\hline NO & - & - & - & - & 1.0 & $0.396 * \star$ & 0.073 & -0.115 & -0.129 & -0.074 & $0.324^{*}$ & -0.007 & $0.305^{*}$ & 0.194 & 0 \\
\hline PC & - & - & - & - & - & 1.0 & 0.052 & -0.003 & -0.165 & -0.047 & $0.441 * *$ & 0.158 & 0.261 & $0.327^{*}$ & 0 \\
\hline SOD3 & - & - & - & - & - & - & 1.0 & -0.271 & 0.035 & 0.126 & -0.045 & 0.020 & 0.082 & 0.173 & $-\mathrm{C}$ \\
\hline GPx3 & - & - & - & - & - & - & - & 1.0 & 0.196 & 0.070 & -0.022 & -0.065 & -0.337 * & $-0.294^{*}$ & $-\mathrm{C}$ \\
\hline CAT & - & - & - & - & - & - & - & - & 1.0 & -0.061 & $-0.439 * *$ & -0.086 & -0.261 & $-0.335^{*}$ & $-\mathrm{C}$ \\
\hline Age & - & - & - & - & - & - & - & - & - & 1.0 & -0.053 & -0.214 & -0.336 * & -0.009 & $-C$ \\
\hline BMI & - & - & - & - & - & - & - & - & - & - & 1.0 & 0.187 & 0.280 * & 0.251 & 0 \\
\hline $\begin{array}{l}\mathrm{a}- \\
\mathrm{HCH}\end{array}$ & - & - & - & - & - & - & - & - & - & - & - & 1.0 & $0.544^{\star \star}$ & $0.333^{*}$ & $-\mathrm{C}$ \\
\hline $\begin{array}{l}\beta- \\
\mathrm{HCH}\end{array}$ & - & - & - & - & - & - & - & - & - & - & - & - & 1.0 & 0.668 ** & 0 \\
\hline $\begin{array}{l}\mathrm{Y}^{-} \\
\mathrm{HCH}\end{array}$ & - & - & - & - & - & - & - & - & - & - & - & - & - & 1.0 & 0 \\
\hline $\begin{array}{l}2,4 \\
\text { DDE }\end{array}$ & - & - & - & - & - & - & - & - & - & - & - & - & - & - & 1 \\
\hline $\begin{array}{l}4,4 \\
\text { DDE }\end{array}$ & - & - & - & - & - & - & - & - & - & - & - & - & - & - & - \\
\hline $\begin{array}{l}2,4 \\
\text { DDT }\end{array}$ & - & - & - & - & - & - & - & - & - & - & - & - & - & - & - \\
\hline $\begin{array}{l}4,4 \\
\text { DDT }\end{array}$ & - & - & - & - & - & - & - & - & - & - & - & - & - & - & - \\
\hline
\end{tabular}

*. Spearman correlation is significant at the 0.05 level (2-tailed).

**. Spearman correlation is significant at the 0.01 level (2-tailed).

Eta co-efficient was used nominal variables.

AChE: Acetylcholinesterase; PON1: Paraoxonase1; MDA: Malondialdehyde; TAC: Total antioxidant capacity. NO: Nitric oxide; PC: Protein carbonyl; SOD3: Sup peroxidase3; CAT: Catalase; a-HCH: a-Hexachlorocyclohexane; $\beta$-HCH: $\beta$-Hexachlorocyclohexane; $\gamma$-HCH: $\gamma$-Hexachlorocyclohexane; 2,4-DDE: 2,4-Dichlorodiph Dichlorodiphenyldichloroethylene; 2,4-DDT: 2,4-Dichlorodiphenyltrichloroethane; 4,4-DDT: 4,4-Dichlorodiphenyltrichloroethane. 
Table 4

Associations of OCPs with oxidative stress

\begin{tabular}{|c|c|c|c|c|c|c|c|c|c|c|c|c|c|c|c|c|}
\hline & \multicolumn{3}{|l|}{$\mathrm{a}-\mathrm{HCH}$} & \multicolumn{3}{|l|}{$\beta-\mathrm{HCH}$} & \multicolumn{3}{|l|}{$\mathrm{y}-\mathrm{HCH}$} & \multicolumn{3}{|c|}{ 2,4 DDE } & \multicolumn{3}{|c|}{ 4,4 DDE } & \multirow{2}{*}{$\begin{array}{l}2 \\
s\end{array}$} \\
\hline & Slope & $95 \% \mathrm{Cl}$ & $\begin{array}{l}P \\
\text { value }\end{array}$ & Slope & $95 \% \mathrm{Cl}$ & $\begin{array}{l}P \\
\text { value }\end{array}$ & Slope & $95 \% \mathrm{Cl}$ & $\begin{array}{l}P \\
\text { value }\end{array}$ & Slope & $95 \% \mathrm{Cl}$ & $\begin{array}{l}P \\
\text { value }\end{array}$ & Slope & $95 \% \mathrm{Cl}$ & $\begin{array}{l}P \\
\text { value }\end{array}$ & \\
\hline AChE & -0.26 & $\begin{array}{l}-0.66- \\
0.01\end{array}$ & 0.05 & -0.34 & $\begin{array}{l}-0.65- \\
-0.08\end{array}$ & 0.01 & -0.32 & $\begin{array}{l}-0.76- \\
-0.07\end{array}$ & 0.01 & -0.18 & $\begin{array}{l}-0.45- \\
0.09\end{array}$ & 0.19 & -0.34 & $\begin{array}{l}-0.48- \\
-0.06\end{array}$ & 0.01 & -0 \\
\hline PON1 & -0.17 & $\begin{array}{l}-3.3- \\
0.78\end{array}$ & 0.22 & -0.47 & $\begin{array}{l}-4.61- \\
-1.39\end{array}$ & $<0.001$ & -0.49 & $\begin{array}{l}-5.67- \\
-1.88\end{array}$ & $<0.001$ & -0.28 & $\begin{array}{l}-3.23- \\
-0.02\end{array}$ & 0.04 & -0.51 & $\begin{array}{l}-3.6- \\
-1.27\end{array}$ & $<0.001$ & -0 \\
\hline MDA & 0.11 & $\begin{array}{l}-0.16- \\
0.38\end{array}$ & 0.42 & 0.36 & $\begin{array}{l}0.07- \\
0.53\end{array}$ & 0.009 & 0.14 & $\begin{array}{l}-0.14- \\
0.43\end{array}$ & 0.3 & 0.42 & $\begin{array}{l}0.12- \\
0.53\end{array}$ & 0.002 & 0.02 & $\begin{array}{l}-0.16- \\
0.19\end{array}$ & 0.88 & 0 . \\
\hline TAC & -0.31 & $\begin{array}{l}-45.49- \\
-2.95\end{array}$ & 0.026 & -0.40 & $\begin{array}{l}-45.88- \\
-9.98\end{array}$ & 0.003 & -0.42 & $\begin{array}{l}-56.39- \\
-13.92\end{array}$ & 0.002 & 0.03 & $\begin{array}{l}-16.07- \\
19.9\end{array}$ & 0.83 & -0.50 & $\begin{array}{l}-38.15- \\
-12.8\end{array}$ & $<0.001$ & -0 \\
\hline NO & -0.01 & $\begin{array}{l}-0.82- \\
0.73\end{array}$ & 0.90 & 0.22 & $\begin{array}{l}-0.12- \\
1.21\end{array}$ & 0.10 & 0.14 & $\begin{array}{l}-0.39- \\
1.23\end{array}$ & 0.30 & 0.32 & $\begin{array}{l}0.10- \\
1.29\end{array}$ & 0.022 & 0.10 & $\begin{array}{l}-0.32- \\
0.69\end{array}$ & 0.46 & 0 . \\
\hline PC & 0.07 & $\begin{array}{l}-0.19- \\
0.33\end{array}$ & 0.58 & 0.32 & $\begin{array}{l}0.03- \\
0.48\end{array}$ & 0.022 & 0.36 & $\begin{array}{l}0.09- \\
0.61\end{array}$ & 0.008 & 0.35 & $\begin{array}{l}0.06- \\
0.46\end{array}$ & 0.011 & 0.24 & $\begin{array}{l}-0.02- \\
0.31\end{array}$ & 0.08 & 0. \\
\hline SOD3 & -0.07 & $\begin{array}{l}-4.07- \\
2.39\end{array}$ & 0.60 & 0.03 & $\begin{array}{l}-2.55- \\
3.14\end{array}$ & 0.83 & 0.04 & $\begin{array}{l}-2.91- \\
3.89\end{array}$ & 0.77 & -0.11 & $\begin{array}{l}-3.58- \\
1.59\end{array}$ & 0.44 & -0.06 & $\begin{array}{l}-2.59- \\
1.63\end{array}$ & 0.64 & -0 \\
\hline GPx3 & -0.01 & $\begin{array}{l}-2.62- \\
2.35\end{array}$ & 0.91 & -0.22 & $\begin{array}{l}-3.88- \\
0.38\end{array}$ & 0.10 & -0.33 & $\begin{array}{l}-5.48- \\
-0.54\end{array}$ & 0.018 & -0.03 & $\begin{array}{l}-2.23- \\
1.79\end{array}$ & 0.81 & -0.17 & $\begin{array}{l}-2.60- \\
0.60\end{array}$ & 0.21 & -0 \\
\hline CAT & -0.17 & $\begin{array}{l}-17.53- \\
3.95\end{array}$ & 0.21 & -0.31 & $\begin{array}{l}-19.46- \\
-1.23\end{array}$ & 0.027 & -0.38 & $\begin{array}{l}-25.82- \\
-4.62\end{array}$ & 0.006 & -0.13 & $\begin{array}{l}-12.82- \\
4.57\end{array}$ & 0.34 & -0.37 & $\begin{array}{l}-15.83- \\
-2.57\end{array}$ & 0.007 & -0 \\
\hline
\end{tabular}

AChE activity was inversely significantly associated with a-HCH, $\beta-\mathrm{HCH}, 4,4-\mathrm{DDE}, 2,4 \mathrm{DDT}$, and 4,4 DDT. PON1 activity was inversely significantly associated v DDT. MDA was positivity significantly associated with $\beta-\mathrm{HCH}, 2,4 \mathrm{DDE}$, and $4,4 \mathrm{DDT}$. TAC was inversely significantly associated with a-HCH, $\beta-\mathrm{HCH}, \gamma-\mathrm{HCH}, 4,4$ significantly associated with $2,4 \mathrm{DDE}$ and $2,4 \mathrm{DDT}$. PC was positivity significantly related to $\beta-\mathrm{HCH}, \gamma-\mathrm{HCH}, 2,4 \mathrm{DDE}$, and $4,4 \mathrm{DDT}$. GPx3 activity was inversely activity was inversely significantly associated with $\beta-\mathrm{HCH}, \mathrm{Y}-\mathrm{HCH}, 4,4-\mathrm{DDE}, 2,4 \mathrm{DDT}$, and 4,4 DDT.

a Cl: confidence interval; Adjusted for BMI and total lipids.

Table 3 presents the overall correlations between the studied parameters. As indicated by the results, AChE activity was negatively correlated with NO levels ( $r$ $=-0.280 ; p<0.05)$, SOD3 activity $(r=-0.285 ; P<0.05)$, and BMI $(r=-0.346 ; P<0.05)$. In addition, PON-1 had a significant positive correlation with GPx3 activity level $(r=0.281, P<0.05)$ and CAT activity level $(r=0.305 ; P<0.05)$. Moreover, MDA levels showed a significant positive association with $P C$ levels $(r=0.287 ; P$ $<0.05)$ and BMI $(r=0.297 ; P<0.01)$, and a negative correlation with CAT activity $(r=-0.314 ; P<0.05)$. TAC had a significant positive relationship with CAT activity $(r=0.288 ; P<0.05)$ and age $(r=0.296 ; P<0.05)$. NO was positively correlated with $P C(r=0.396 ; P<0.01)$ and BMI $(r=0.324 ; P<0.05)$. Furthermore, a negative significant correlation was seen between CAT activity and BMI $(r=-0.439 ; P<0.01)$.

In addition, the results indicated that $\mathrm{\gamma}-\mathrm{HCH}(r=-0.283 ; \mathrm{P}<0.05), 4,4 \mathrm{DDE}(r=-0.325 ; \mathrm{P}<0.05), 2,4$ DDT $(r=-0.303 ; \mathrm{P}<0.05)$, and 4,4 DDT $(r=-0.459 ; \mathrm{P}<0.01)$ were negatively correlated with AChE activity. However, $\beta-H C H(r=-0.320 ; P<0.05), \gamma-H C H(r=-0.348 ; P<0.05), 2,4$ DDE $(r=-0.325 ; P<0.05), 4,4$ DDE $(r=$ $-0.394 ; \mathrm{P}<0.01)$, and 2,4 DDT $(r=-0.385 ; \mathrm{P}<0.01)$ had a negative correlation with PON-1 activity. Furthermore, 2,4 DDE $(r=0.327 ; \mathrm{P}<0.05)$ and 4,4 DDT $(r=$ $0.461 ; \mathrm{P}<0.01)$ exhibited a positive significant association with MDA levels. Moreover, TAC had a significant negative correlation with $a-H C H(r=-0.310 ; P<$ $0.05), \beta-H C H(r=-0.394 ; P<0.01), y-H C H(r=-0.412 ; P<0.01), 4,4$ DDE $(r=-0.437 ; P<0.01)$, and 2,4 DDT $(r=-0.434 ; P<0.01)$. Data also showed that the NO level had a direct significant relationship with $\beta-\mathrm{HCH}(r=0.305 ; P<0.05), 2,4 \mathrm{DDE}(r=0.280 ; P<0.05)$, and 4,4 DDT ( $r=0.516 ; \mathrm{P}<0.01)$. It was observed that the PC level was positively correlated with $\mathrm{Y}-\mathrm{HCH}(r=0.327$; $\mathrm{P}<0.05), 2,4 \mathrm{DDE}(r=0.351 ; \mathrm{P}<0.05)$, and 4,4 DDT $(r=0.512 ; \mathrm{P}<0.01)$. The GPx3 activity level had a significant negative relation with $\beta-\mathrm{HCH}(r=-0.437 ; \mathrm{P}<0.01)$ and $\mathrm{\gamma}-\mathrm{HCH}(r=-0.437 ; \mathrm{P}<0.01)$. Moreover, $\gamma-\mathrm{HCH}(r=-0.335 ; \mathrm{P}<0.05), 4,4 \mathrm{DDE}(r=-0.288$; $P<0.05)$, and 4,4 DDT $(r=-0.461 ; P<0.01)$ had a significant negative correlation with the CAT activity level. Finally, age was shown to be negatively associated with $\beta-\mathrm{HCH}(r=-0.336 ; \mathrm{P}<0.05)$ and $2,4 \mathrm{DDT}(r=-0.388 ; \mathrm{P}<0.01)$.

Table 4 demonstrates the correlation of oxidant and antioxidant parameters with OCP levels. Data showed a negative significant association between 4,4 DDE and AChE activity $(P=0.011)$. The results also indicated that $N O$ and $P C$ levels had a positive correlation with 2,4 DDT $(P=043)$ and 4,4 DDT $(P=0.003)$, respectively. However, MDA, TAC, PON-1, SOD, GPx, and CAT activity levels did not show any correlation with the measured OCP levels $(\mathrm{P}>0.05)$.

To assess the effects of pesticide exposure on OS parameters, a linear regression analysis was used (Table 4). AChE activity showed a significant inverse relationship with a- $\mathrm{HCH}(\beta=-0.26, \mathrm{P}=0.05), \beta-\mathrm{HCH}(\beta=-0.34, \mathrm{P}=0.01), \mathrm{\gamma}-\mathrm{HCH}(\beta=-0.32, \mathrm{P}=0.01), 4,4 \mathrm{DDE}(\beta=-0.34, \mathrm{P}=0.01), 2,4 \mathrm{DDT}(\beta=-0.44, \mathrm{P}=0.001)$, and $4,4 \mathrm{DDT}(\beta=-0.63, \mathrm{P}=0.001)$. The regression results also showed that the PON-1 activity had an inverse significant association with $\beta$-HCH $(\beta=-0.47, \mathrm{P}<$ $0.001), \gamma-\mathrm{HCH}(\beta=-0.49, \mathrm{P}<0.001), 2,4 \mathrm{DDE}(\beta=-0.28, \mathrm{P}=0.04), 4,4-\mathrm{DDE}(\beta=-0.51, \mathrm{P}<0.001), 2,4 \mathrm{DDT}(\beta=-0.34, \mathrm{P}=0.01)$, and 4,4 DDT $(\beta=-0.38, \mathrm{P}=$ 0.005). TAC activity showed an inverse significant relationship with $\alpha-\mathrm{HCH}(\beta=-0.31, \mathrm{P}<0.026), \beta-\mathrm{HCH}(\beta=-0.40, \mathrm{P}<0.003), \gamma-\mathrm{HCH}(\beta=-0.42, \mathrm{P}=0.002), 4,4$ $\operatorname{DDE}(\beta=-0.50, P<0.001), 2,4 \operatorname{DDT}(\beta=-0.47, P<0.001)$, and 4,4 DDT $(\beta=-0.32, P=0.022)$. Moreover, NO had a significant relationship with 2,4 DDE $(\beta=0.32$, $P=0.022)$ and 4,4 DDT $(\beta=0.51, P=0.001)$. GPx3 activity was shown to have an inverse relationship with $\gamma-\mathrm{HCH}(\beta=-0.33, \mathrm{P}=0.018)$ and $4,4 \mathrm{DDT}(\beta=-0.29$, $P=0.036)$. CAT activity also had an inverse relationship with $\beta-\mathrm{HCH}(\beta=-0.31, P=0.027), \mathrm{Y}-\mathrm{HCH}(\beta=-0.38, P=0.006), 4,4 \mathrm{DDE}(\beta=-0.37, \mathrm{P}=0.007), 2,4 \mathrm{DDT}$ $(\beta=-0.37, P=0.007)$, and 4,4 DDT $(\beta=-0.59, P<0.001)$. 
MDA level had a positive significant association with $\beta-\mathrm{HCH}(\beta=0.36, P=0.009), 2,4 \mathrm{DDE}(\beta=0.42, P=0.002)$, and 4,4 DDT ( $\beta=0.59, \mathrm{P}<0.001)$. In addition, $\mathrm{PC}$ was positively associated with $\beta-\mathrm{HCH}(\beta=0.32, \mathrm{P}=0.022), \mathrm{Y}-\mathrm{HCH}(\beta=0.36, \mathrm{P}=0.008), 2,4 \mathrm{DDE}(\beta=0.35, \mathrm{P}=0.011)$, and 4,4-DDT $(\beta=0.50, \mathrm{P}<0.001)$. SOD3 activity had no significant association with OCPs.

Logistic regression analysis revealed that higher levels of OCPs were linked to an increased risk of lung cancer (Table 5). Moreover, analyses were adjusted for potential confounding factors, which included BMI, TG, and cholesterol. Lung cancer was associated with a- $\mathrm{HCH}$ (multivariable-adjusted OR $=3.19,95 \% \mathrm{Cl}$ : 1.77-5.75, $\mathrm{P}<0.001), \beta-\mathrm{HCH}(\mathrm{OR}=5.68,95 \% \mathrm{Cl}: 2.71-11.90, \mathrm{P}<0.001), \mathrm{\gamma}-\mathrm{HCH}(\mathrm{OR}=5.64,95 \% \mathrm{Cl}: 2.55-12.47, \mathrm{P}<0.001), 2,4 \mathrm{DDE}(\mathrm{OR}=6.40,95 \% \mathrm{Cl}: 2.93-$ 13.94, $\mathrm{P}<0.001), 4,4 \mathrm{DDE}(\mathrm{OR}=3.80,95 \% \mathrm{Cl}: 2.11-6.86, \mathrm{P}<0.001), 2,4 \mathrm{DDT}(\mathrm{OR}=5.13,95 \% \mathrm{Cl}: 2.58-10.17, \mathrm{P}<0.001)$, and 4, 4 DDT (OR = 3.72, 95\% Cl: 2.71$6.39, \mathrm{P}<0.001)$. 
Table 5

Association between lung cancer incidence and OCPs by quartiles.

\begin{tabular}{|c|c|c|c|c|c|c|c|c|}
\hline & \multicolumn{4}{|l|}{ Crude } & \multicolumn{4}{|c|}{ Adjusted } \\
\hline & $B$ & OR & Cl-95\% & $P$-value & $B$ & OR & $\mathrm{Cl}-95 \%$ & $P$-value \\
\hline $\mathrm{a}-\mathrm{HCH}$ & 0.27 & 1.31 & $19-1.44$ & $<0.001$ & 1.16 & 3.19 & $1.77-5.75$ & $<0.001$ \\
\hline $\mathrm{Q} 1(\leq 0.92)$ & Ref & 2.64 & $0.94-7.40$ & 0.064 & Ref & 5.12 & $1.39-18.74$ & 0.014 \\
\hline Q2(0.93-1.30) & 0.97 & 2.85 & $0.92-8.80$ & 0.068 & 1.63 & 2.56 & $0.67-9.79$ & 0.16 \\
\hline Q3(1.31-2.36) & 1.04 & 5.40 & $1.58-18.39$ & 0.007 & 0.94 & 5.59 & $1.31-23.80$ & 0.02 \\
\hline $\begin{array}{l}\mathrm{Q} 4(>2.36) \\
p \text { for trend }\end{array}$ & 1.68 & & & & 1.72 & & & \\
\hline$\beta-\mathrm{HCH}$ & 0.43 & 1.53 & $1.31-1.79$ & $<0.001$ & 1.73 & 5.68 & $2.71-11.90$ & $<0.001$ \\
\hline $\mathrm{Q} 1(\leq 0.57)$ & Ref 0.511 .53 & 1.66 & $0.51-5.39$ & 0.39 & Ref & 3.97 & $0.81-19.53$ & $0 ., 08$ \\
\hline Q2(0.58-1.08) & 1.80 & 4.64 & $1.46-14.76$ & 0.009 & 1.38 & 19.50 & $3.25-116.8$ & 0.001 \\
\hline $\begin{array}{l}\text { Q3(1.09-2.91) } \\
\text { Q4(>2.91) } \\
p \text { for trend }\end{array}$ & & 6.07 & $1.96-18.72$ & 0.002 & $\begin{array}{l}2.97 \\
2.76\end{array}$ & 15.87 & $3.45-72.94$ & $<0.001$ \\
\hline $\mathrm{Y}-\mathrm{HCH}$ & 0.44 & 1.56 & $1.31-1.79$ & $<0.001$ & 1.73 & 5.64 & $2.55-12.47$ & $<0.001$ \\
\hline $\mathrm{Q} 1(\leq 0.35)$ & Ref & 0.67 & $0.22-2.01$ & 0.47 & Ref & 0.57 & $0.15-2.21$ & 0.42 \\
\hline Q2(0.36-1.22) & -0.39 & 1.75 & $0.52-5.84$ & 0.36 & -0.54 & 1.07 & $0.26-4.40$ & 0.91 \\
\hline Q3(1.23-2.14) & 0.56 & 6.44 & $1.99-20.79$ & 0.002 & 0.07 & 7.36 & $1.85-29.17$ & 0.005 \\
\hline $\begin{array}{l}\mathrm{Q} 4(>2.14) \\
p \text { for trend }\end{array}$ & 1.86 & & & & 1.99 & & & \\
\hline 2,4-DDE & 0.18 & 1.21 & $1.13-1.28$ & $<0.001$ & 1.85 & 6.40 & $2.93-13.94$ & $<0.001$ \\
\hline $\mathrm{Q} 1(\leq 0.95)$ & Ref & 2.07 & $0.69-6.22$ & 0.19 & Ref & 4.52 & $1.13-17.98$ & 0.03 \\
\hline Q2(0.96-1.72) & 0.73 & 3.56 & $1.13-11.16$ & 0.02 & 1.50 & 8.51 & $1.87-38.74$ & 0.006 \\
\hline Q3(1.73-2.62) & 1.27 & 4.74 & $1.56-14.36$ & 0.006 & 2.14 & 9.76 & $2.31-41.24$ & 0.002 \\
\hline $\begin{array}{l}\mathrm{Q} 4(>2.62) \\
p \text { for trend }\end{array}$ & 1.55 & & & & 2.27 & & & \\
\hline 4,4-DDE & 0.64 & 1.91 & $1.48-2.45$ & $<0.001$ & 1.33 & 3.80 & $2.11-6.86$ & $<0.001$ \\
\hline $\mathrm{Q} 1(\leq 0.86)$ & Ref & 1.05 & $0.32-3.41$ & 0.92 & Ref & 2.22 & $0.55-8.96$ & 0.26 \\
\hline Q2(0.87-1.62) & 0.05 & 3.54 & $1.09-11.46$ & 0.03 & 0.79 & 7.04 & $1.54-32.14$ & 0.012 \\
\hline Q3(1.63-4.27) & 1.26 & 7.34 & $2.29-23.57$ & 0.001 & 1.95 & 12.74 & $2.71-59.88$ & 0.001 \\
\hline $\begin{array}{l}\text { Q4(>4.27) } \\
p \text { for trend }\end{array}$ & 1.99 & & & & 2.54 & & & \\
\hline 2,4-DDT & 0.15 & 1.16 & $1.07-1.27$ & $<0.001$ & 1.63 & 5.13 & $2.58-10.17$ & $<0.001$ \\
\hline $\mathrm{Q} 1(\leq 1.36)$ & Ref & 1.63 & $0.57-4.66$ & 0.35 & Ref & 1.82 & $0.51-6.48$ & 0.35 \\
\hline Q2(1.37-1.64) & 0.49 & 4.76 & $1.54-14.64$ & 0.006 & 0.59 & 5.16 & $1.36-19.57$ & 0.016 \\
\hline Q3(1.65-3.77) & 1.56 & 5.00 & $1.43-17.45$ & 0.012 & 1.64 & 7.20 & $1.53-33.81$ & 0.012 \\
\hline $\begin{array}{l}\text { Q4(>3.77) } \\
p \text { for trend }\end{array}$ & 1.60 & & & & 1.97 & & & \\
\hline
\end{tabular}




\begin{tabular}{|c|c|c|c|c|c|c|c|c|}
\hline & Crude & & & & Adjus & & & \\
\hline 4,4-DDT & 0.21 & 1.24 & $1.11-1.38$ & $<0.001$ & 1.31 & 3.72 & $2.17-6.39$ & $<0.001$ \\
\hline $\mathrm{Q} 1(\leq 1.42)$ & Ref & 1.03 & $0.31-3.42$ & 0.95 & Ref & 1.75 & $0.42-7.27$ & 0.44 \\
\hline Q2(1.43-2.33) & 0.03 & 3.33 & $1.08-10.23$ & 0.03 & 0.55 & 3.40 & $0.93-12.42$ & 0.064 \\
\hline Q3(2.34-4.61) & 1.20 & 7.40 & $2.22-24.70$ & 0.001 & 1.22 & 6.44 & $1.62-25.57$ & 0.008 \\
\hline $\begin{array}{l}\mathrm{Q} 4(>4.61) \\
p \text { for trend }\end{array}$ & 2.00 & & & & 1.86 & & & \\
\hline
\end{tabular}

\section{Discussion}

Lung cancer is one of the major health issues worldwide. Although the primary etiology of lung cancer development has not been elucidated completely, it is widely accepted that multiple risk factors including genetic and environmental factors are linked to its development (Luo et al., 2011). Recently, pesticide exposure has been considered a new cancer risk factor (Abolhassani et al., 2019; Mortazavi et al., 2019b; Paydar et al., 2019). The present study was designed to compare the levels of OCPs, OPPs, and OS components between patients with lung cancer and healthy subjects.

The most remarkable finding of the present work was that the mean serum levels of the seven studied OCPs in patients with lung cancer were significantly higher than in the healthy subjects (Table 2 and Figure 2). These results were consistent with those of other studies that showed OCP serum concentrations in patients with cancer were higher than in the healthy subjects (Attaullah et al., 2018; Verma et al., 2018; Wielsøe et al., 2017). Hence, it seems that there is a significant association between the serum levels of OCPs and cancer incidence.

Due to the tendency of OCPs for accumulation in the body fat masses, the lipid profile and BMI can be considered two main confounding factors in OCP measurement (Paydar et al., 2019; Pelletier et al., 2002). However, the results of this study showed significant differences in the lipid profile and BMI between patients with lung cancer and healthy subjects (Table 1). Therefore, logistic regression analysis was performed by adjusting for BMI, TG, and cholesterol. These factors increased the risk of lung cancer, according to the findings.

To evaluate OPP exposure levels, determining the AChE activity is the standard method (Majidi et al., 2018; Moon et al., 2015). In the present study, a significant decrease in AChE activity was observed in patients with lung cancer compared to the healthy subjects (Figure 1). Consistent with our results, several studies showed that AChE activity was reduced in lung cancer patients (Xi et al., 2015). The participation of AChE in the apoptosis process, as an unconventional function of this enzyme, has been confirmed in previous studies (Jiang \& Zhang, 2008). In this context, it has been reported that the downregulation of AChE by small interfering ribonucleic acids (siRNAs) could inhibit the apoptosis process (Park et al., 2004). Thus, the decrease of AChE activity may lead to tumor development by inhibiting the apoptosis process (Shehadeh Mashour et al., 2012).

However, the results showed significant differences in oxidant and antioxidant criteria between the two groups, except for SOD activity. MDA, NO, and PC levels were significantly higher in patients with lung cancer compared to healthy subjects while PON-1, GPx, and CAT activity levels and TAC levels were significantly lower in lung cancer patients compared to healthy controls.

There were no significant differences in total protein concentrations between patients with lung cancer and healthy individuals (Table 1). Our data showed a significant increase in PC levels in patients with lung cancer compared with healthy subjects (Figure 1). PC is an important sign of protein oxidative damages. This result is supported by previous studies which indicated that protein damages and protein dysfunction were linked to cancer development (McAdam et al., 2016). As shown in Table 1, the lipid profile (HDL-C and LDL-C) in patients with lung cancer did not show any significant differences compared to healthy subjects, while TG and cholesterol serum levels showed significant differences between the two groups. Therefore, logistic regression analysis was performed, by adjusting for BMI, TG, and cholesterol, to eliminate the effects of confounding factors. A significant increase in MDA concentration level was observed in patients with lung cancer compared to the control group (Figure 1, Table 3). Since MDA can be considered a parameter of lipid damage, it has been reported that MDA concentration is clearly higher in cancer patients compared to healthy controls (Abolhassani et al., 2019; Gönenç et al., 2001; Mortazavi et al., 2019b). Due to the high level of OCPs and the evidence of OPP exposure in patients with lung cancer, we concluded that the main reason for the high levels of MDA is the evaluated pesticides.

On the other hand, our results showed that enzymatic (GPx, CAT, AChE, and PON-1) and non-enzymatic (TAC) antioxidant factors were significantly lower in cancer patients compared to healthy subjects (Figure 1). The findings observed in this study mirror those of our previous studies, which indicated a significant reduction in antioxidant parameters such as GPx, CAT, AChE, PON-1, and TAC in cancer patients compared with healthy individuals (Abolhassani et al., 2019; Mortazavi et al., 2019b; Paydar et al., 2019). However, according to the results, exposure to OCPs and OPPs led to redox imbalance, which might consequently lead to lung cancer development. 
Although the current study is based on a small sample of participants, the findings suggest that serum levels of the studied pesticides and the redox condition have a major role in promoting lung cancer. However, future research needs to more closely examine the links between serum levels of pesticides and redox condition and lung cancer development.

\section{Conclusion}

The most important finding of the present study was that the mean serum levels of the seven studied OCPs, which are illegal, were significantly higher in patients with lung cancer than in the healthy subjects. On the other hand, AChE and PON-1 activity, which are important indices for OPP exposure, were significantly lower in lung cancer patients compared with healthy individuals. Furthermore, antioxidant parameters such as GPx, CAT, and TAC were lower and MDA, as the final product of lipid peroxidation, was higher in cancer patients when compared with the healthy group. Therefore, based on the obtained results, it may be concluded that exposure to OCPs and OPPs led to the development of advanced oxidation processes and redox imbalance, resulting in lung cancer development.

\section{Declarations}

\section{Ethics approval and consent to participate}

This research followed the principles of the amended Helsinki Declaration (2013) which is a statement of ethical concepts to supply guidance to physicians and participants in human-involved medical studies and confirmed by the Ethics Committee of Kerman University of Medical Sciences, Kerman, Iran (IR.KMU.REC. 1398.335). All participants have consciously signed the consent form.

Authors' Contribution: Moslem Abolhassani and Gholamreza Asadikaram conceived the study and designed the survey and provided continuous guidance throughout the study and interpreted the data. Mojtaba Abbasi-Jorjandi, Sanaz Faramarz and Fatemeh Yousefi collected samples. Moslem Abolhassani and Fouzieh Salimi performed all experiments, oversaw data collection and analysis, and drafted the manuscript. Hossein Pourghdamyari, Reza Malekpour Afshar, Parisa Asadikaram, and Mohsen Shafiepour helped the survey and analyzed data. All authors have participated in the revisions of the manuscript and have approved the final version.

\section{Acknowledgement}

As a sign of gratitude for their cooperation, we would like to thank subjects participating in this study.

\section{Declaration of interest}

The authors declare no conflict of interest.

\section{Data availability:}

The datasets used during the current study are available from the corresponding author on reasonable request.

\section{Funding:}

The present project supported by a grant provided by the Kerman University of Medical sciences (project number: 96001011).

\section{Consent for publication}

All participants agree to publish this article.

\section{References}

1. Abolhassani M, Asadikaram G, Paydar P, Fallah H, Aghaee-Afshar M, Moazed V, Akbari H, Moghaddam SD, Moradi A (2019) Organochlorine and organophosphorous pesticides may induce colorectal cancer; A case-control study. Ecotoxicol Environ Saf 178:168-177

2. Attaullah M, Yousuf MJ, Shaukat S, Anjum SI, Ansari MJ, Buneri ID, Tahir M, Amin M, Ahmad N, Khan SU (2018) Serum organochlorine pesticides residues and risk of cancer: A case-control study. Saudi Journal of Biological Sciences 25:1284-1290

3. Basumallik N, Agarwal M (2019) Cancer, Lung Small Cell (Oat Cell), StatPearls [Internet]. StatPearls Publishing

4. Benzie IF, Strain JJ (1996) The ferric reducing ability of plasma (FRAP) as a measure of "antioxidant power": the FRAP assay. Anal Biochem 239:70-76

5. Bhardwaj JK, Mittal M, Saraf P, Kumari P (2018) : Pesticides induced oxidative stress and female infertility: a review.Toxin Reviews,1-13

6. Bobin-Dubigeon C, Jaffré I, Joalland M-P, Classe J-M, Campone M, Hervé M, Bard J-M (2012) Paraoxonase 1 (PON1) as a marker of short term death in breast cancer recurrence. Clin Biochem 45:1503-1505

7. Boice JD Jr, Ellis ED, Golden AP, Zablotska LB, Mumma MT, Cohen SS (2019) : Sex-specific lung cancer risk among radiation workers in the million-person study and patients TB-Fluoroscopy.International journal of radiation biology,1-12

8. Buege JA, Aust SD (1978) [30] Microsomal lipid peroxidation, Methods in enzymology. Elsevier, pp 302-310

9. Cannon-Albright LA, Carr SR, Akerley W (2019) Population-based Relative Risks for Lung Cancer Based on Complete Family History of Lung Cancer. Journal of Thoracic Oncology 
10. Cramb SM, Baade PD, White NM, Ryan LM, Mengersen KL (2015) Inferring lung cancer risk factor patterns through joint Bayesian spatio-temporal analysis. Cancer Epidemiol 39:430-439

11. Deng S, Chen Y, Wang D, Shi T, Wu X, Ma X, Li X, Hua R, Tang X, Li QX (2015) Rapid biodegradation of organophosphorus pesticides by Stenotrophomonas sp. G1. J Hazard Mater 297:17-24

12. Friedewald WT, Levy RI, Fredrickson DS (1972) Estimation of the concentration of low-density lipoprotein cholesterol in plasma, without use of the preparative ultracentrifuge. Clin Chem 18:499-502

13. Gönenç A, Özkan Y, Torun M, Şimşek B (2001) Plasma malondialdehyde (MDA) levels in breast and lung cancer patients. J Clin Pharm Ther 26:141-144

14. Hadian Z, Eslamizad S, Yazdanpanah H (2019) Pesticide residues analysis in Iranian fruits and vegetables by Gas Chromatography-Mass Spectrometry. Iranian Journal of Pharmaceutical Research 18:275-285

15. He T-T, Zuo A-J, Wang J-G, Zhao P (2017) Organochlorine pesticides accumulation and breast cancer: A hospital-based case-control study. Tumor Biology 39:1010428317699114

16. Jayaraj R, Megha P, Sreedev P (2016) Organochlorine pesticides, their toxic effects on living organisms and their fate in the environment. Interdisciplinary toxicology 9:90-100

17. Jiang H, Zhang XJ (2008) Acetylcholinesterase and apoptosis: a novel perspective for an old enzyme. FEBS J 275:612-617

18. Kobrosly RW, Evans S, Miodovnik A, Barrett ES, Thurston SW, Calafat AM, Swan SH (2014) Prenatal phthalate exposures and neurobehavioral development scores in boys and girls at 6-10 years of age. Environ Health Perspect 122:521-528

19. Levine RL, Garland D, Oliver CN, Amici A, Climent I, Lenz A-G, Ahn B-W, Shaltiel S, Stadtman ER (1990) [49] Determination of carbonyl content in oxidatively modified proteins. Methods Enzymol 186:464-478

20. Lima JE, Xavier DJ, Sakamoto-Hojo ET (2019) : Oxidative Stress, DNA Damage and Repair Pathways in Patients with Type 2 Diabetes Mellitus, Type 2 Diabetes. IntechOpen

21. Luo J, Hendryx M, Ducatman A (2011) : Association between six environmental chemicals and lung cancer incidence in the United States. Journal of environmental and public health 2011

22. Majidi M, Delirrad M, Mohammadi AB, Najafi MN, Nekoueifard S, Alizadeh A, Dadpour B (2018) : Cholinesterase Level in Erythrocyte or Serum: Which is More Predictive of the Clinical Outcome in Patients with Acute Organophosphate Poisoning?Age (years)27, 42.2

23. Mao Y, Yang D, He J, Krasna MJ (2016) Epidemiology of lung cancer. Surgical Oncology Clinics 25:439-445

24. Mardani R, Jafari Najaf Abadi MH, Motieian M, Taghizadeh-Boroujeni S, Bayat A, Farsinezhad A, Gheibi Hayat SM, Motieian M, Pourghadamyari H (2019) MicroRNA in leukemia: Tumor suppressors and oncogenes with prognostic potential. J Cell Physiol 234:8465-8486

25. Martin FL, Martinez EZ, Stopper H, Garcia SB, Uyemura SA, Kannen V (2018) Increased exposure to pesticides and colon cancer: Early evidence in Brazil. Chemosphere 209:623-631

26. McAdam E, Brem R, Karran P (2016) Oxidative stress-induced protein damage inhibits DNA repair and determines mutation risk and therapeutic efficacy. Mol Cancer Res 14:612-622

27. Miranda-Filho A, Piñeros M, Bray F (2019) The descriptive epidemiology of lung cancer and tobacco control: a global overview 2018. salud pública de méxico 61:219-229

28. Mirzaei HR, Pourghadamyari H, Rahmati M, Mohammadi A, Nahand JS, Rezaei A, Mirzaei H, Hadjati J (2018) Gene-knocked out chimeric antigen receptor (CAR) T cells: tuning up for the next generation cancer immunotherapy. Cancer Lett 423:95-104

29. Moohebati M, Falsoleiman H, Dehghani M, Fazlinezhad A, Daloee MH, Esmaeili H, Parizadeh SMR, Tavallaie S, Rahsepar AA, Paydar R (2011) Serum inflammatory and immune marker response after bare-metal or drug-eluting stent implantation following percutaneous coronary intervention. Angiology 62:184-190

30. Moon J, Chun B, Lee S (2015) Variable response of cholinesterase activities following human exposure to different types of organophosphates. Hum Exp Toxicol 34:698-706

31. Mortazavi N, Asadikaram G, Ebadzadeh MR, Kamalati A, Pakmanesh H, Dadgar R, Moazed V, Paydar P, Fallah H, Abolhassani M (2019a) Organochlorine and organophosphorus pesticides and bladder cancer: A case-control study. J Cell Biochem 120:14847-14859

32. Mortazavi N, Asadikaram G, Ebadzadeh MR, Kamalati A, Pakmanesh H, Dadgar R, Moazed V, Paydar P, Fallah H, Abolhassani M (2019b) Organochlorine and organophosphorus pesticides and bladder cancer: A case-control study. Journal of cellular biochemistry

33. Paglia DE, Valentine WN (1967) Studies on the quantitative and qualitative characterization of erythrocyte glutathione peroxidase. J Lab Clin Med 70:158-169

34. Park SE, Kim ND, Yoo YH (2004) Acetylcholinesterase plays a pivotal role in apoptosome formation. Cancer Res 64:2652-2655

35. Paydar P, Asadikaram G, Zeynali Nejad H, Moazed V, Poursayedi B, Nematollahi MH, Akbari H, Abolhassani M, Khosravi Shadmani F (2018) : The role of acetylcholinesterase, paraoxonase, and oxidative stress in breast tumors.International Journal of Cancer Management11

36. Paydar P, Asadikaram G, Fallah H, Nejad HZ, Akbari H, Abolhassani M, Moazed V, Khazaeli P, Heidari MR (2019) : Serum levels of Organochlorine Pesticides and Breast Cancer Risk in Iranian Women.Archives of environmental contamination and toxicology, 1-10

37. Pelletier C, Després J-P, Tremblay A (2002) Plasma organochlorine concentrations in endurance athletes and obese individuals. Med Sci Sports Exerc 34:1971-1975

38. Peppers SB (2019) :Can Pesticides Cause Prostate Cancer? Prostate

39. Phillips R, Zeleznik J, Dunn G, Quisenberry V (1989) Mechanism of water entry into simulated macropores. Soil Sci Soc Am J 53:1629-1635

Page 16/20 
40. Pirsaheb M, Limoee M, Namdari F, Khamutian R (2015) Organochlorine pesticides residue in breast milk: a systematic review. Medical journal of the Islamic Republic of Iran 29:228

41. Rezaeigolestani M, Hashemi M (2018) A Review of Pesticide Residues in Agricultural and Food Products of Iran. Journal of Nutrition, Fasting and Health 6:1-6

42. Rui Y, Wu X, Ma B, Xu Y (2018) Immobilization of acetylcholinesterase on functionalized SBA-15 mesoporous molecular sieve for detection of organophosphorus and carbamate pesticide. Chin Chem Lett 29:1387-1390

43. Rybarczyk-Kasiuchnicz A, Ramlau R (2018) Current views on molecularly targeted therapy for lung cancer-a review of literature from the last five years. Kardiochirurgia i Torakochirurgia Polska= Polish Journal of Cardio-Thoracic Surgery 15:119

44. Shehadeh Mashour R, Heinrich R, Garzozi HJ, Perlman I (2012) Acetylcholinesterase (AChE) is an important link in the apoptotic pathway induced by hyperglycemia in Y79 retinoblastoma cell line. Front Mol Neurosci 5:69

45. Siddiqui F, Siddiqui AH (2019) : Cancer, Lung, StatPearls [Internet]. StatPearls Publishing

46. Siegel RL, Miller KD, Jemal A (2016) Cancer statistics, 2016. Cancer J Clin 66:7-30

47. Singh Z, Kaur J, Kaur R, Hundal SS (2016) Toxic effects of organochlorine pesticides: a review. Am J Biosci 4:11-18

48. Sinha AK (1972) Colorimetric assay of catalase. Anal Biochem 47:389-394

49. Tahmasebi-Birgani MJ, Teimoori A, Ghadiri A, Mansoury-Asl H, Danyaei A, Khanbabaei H (2019) Fractionated radiotherapy might induce epithelialmesenchymal transition and radioresistance in a cellular context manner. J Cell Biochem 120:8601-8610

50. Valdez CA, Nicholas AB, Malfatti MA, Enright HA, Bennion BJ, Carpenter TS, Hok S, leong Lao H, Nguyen TH (2019) Compounds for central reactivation of organophosphorus-based compound-inhibited acetylcholinesterase and/or inactivation of organophosphorus-based acetylcholinesterase inhibitors and related compositions methods and systems for making and using them. Google Patents

51. Verma H, Sharma T, Gupta S, Banerjee B (2018) CYP1A1 expression and organochlorine pesticides level in the etiology of bladder cancer in North Indian population. Hum Exp Toxicol 37:817-826

52. Wei L, Li N, Wang G, Su K, Li F, Chang S, Tan F, Lyu Z, Feng X, Li X (2018) Alcohol consumption and the risk of lung cancer in males: a prospective cohort study. Zhonghua liu xing bing xue za zhi=. Zhonghua liuxingbingxue zazhi 39:909

53. Wielsøe M, Kern P, Bonefeld-Jørgensen EC (2017) Serum levels of environmental pollutants is a risk factor for breast cancer in Inuit: a case control study. Environ Health 16:56

54. Worek F, Mast U, Kiderlen D, Diepold C, Eyer P (1999) Improved determination of acetylcholinesterase activity in human whole blood. Clin Chim Acta 288:73-90

55. Xi HJ, Wu RP, Liu JJ, Zhang LJ, Li ZS (2015) Role of acetylcholinesterase in lung cancer. Thoracic cancer 6:390-398

56. Yang Y, Dong J, Sun K, Zhao L, Zhao F, Wang L, Jiao Y (2013) Obesity and incidence of lung cancer: a meta-analysis. Int J Cancer 132:1162-1169

57. Yucel AA, Gulen S, Dincer S, Yucel AE, Yetkin GI (2012) Comparison of two different applications of the Griess method for nitric oxide measurement. J Exp Integr Med 2:1

\section{Figures}



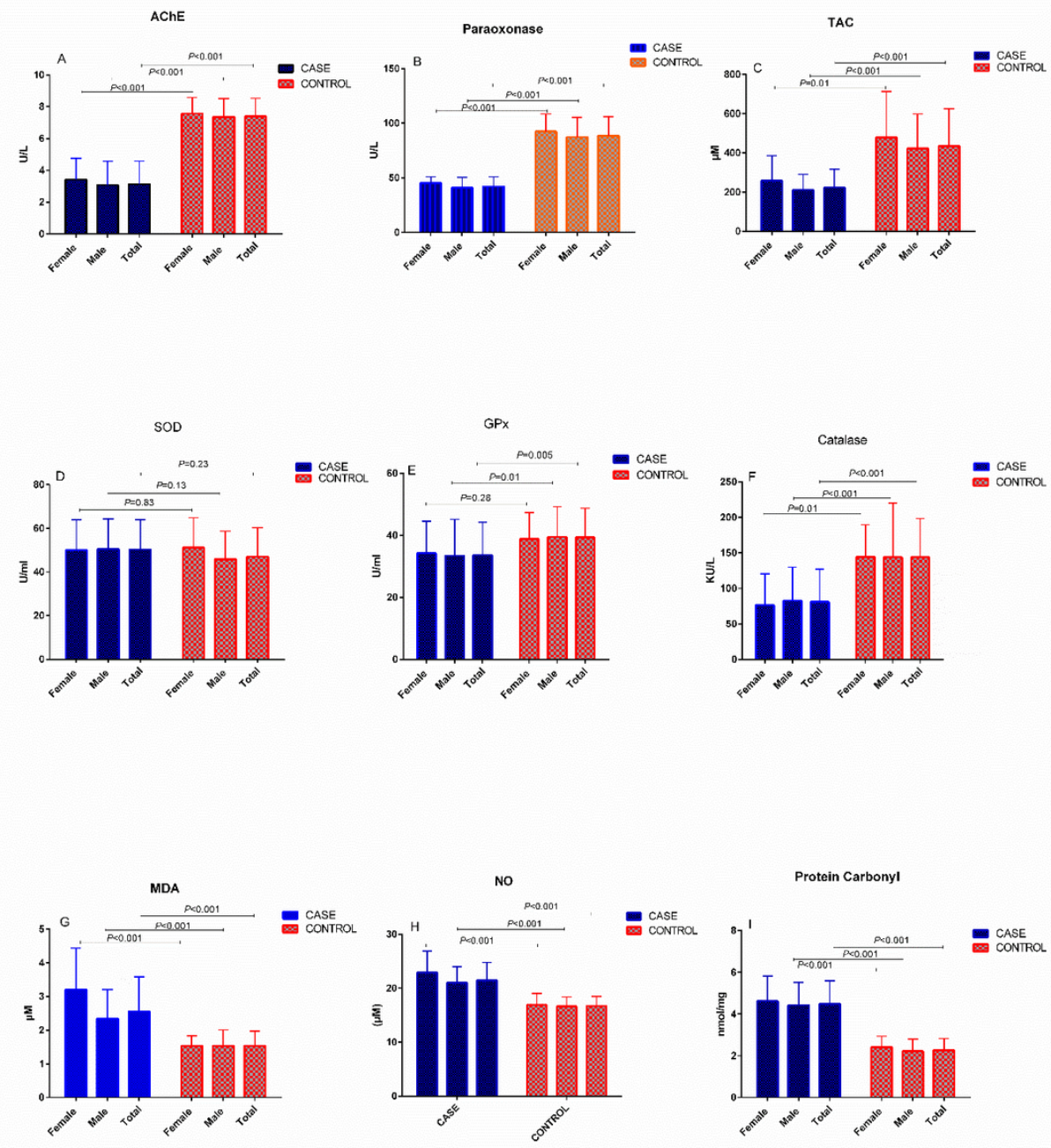

\section{Figure 1}

The charts display information about some OS factors in lung cancer and healthy subjects. (a) AChE activity was significantly decreased in the patient groups compared to the control group. (b) Decreased PON1 arylesterase activity in the patient group than the control subject. (c) The levels of TAC ( $\mu \mathrm{M}$ ) of lung cancer were significantly decreased in comparison to the healthy control. (d) With respect to the SOD3 bar chart, the SOD3 activity in the patient group was not different from the control group. (e) The mean serum activity of GPX3 decreased in the lung cancer than the control group excluding female. (f) CAT activity was significantly lower in the patient group rather than the control one. $(\mathrm{g})$ The levels of $\mathrm{MDA}(\mu \mathrm{M} / \mathrm{ml})$ in lung cancer were significantly increased in comparison to the healthy control. (h) The levels of $\mathrm{NO}(\mu \mathrm{mol} / \mathrm{L})$ of lung cancer were significantly increased in comparison to the healthy control. (i) The levels of protein carbonyl (nmol/mg protein) of lung cancer were significantly increased in comparison to healthy control. 

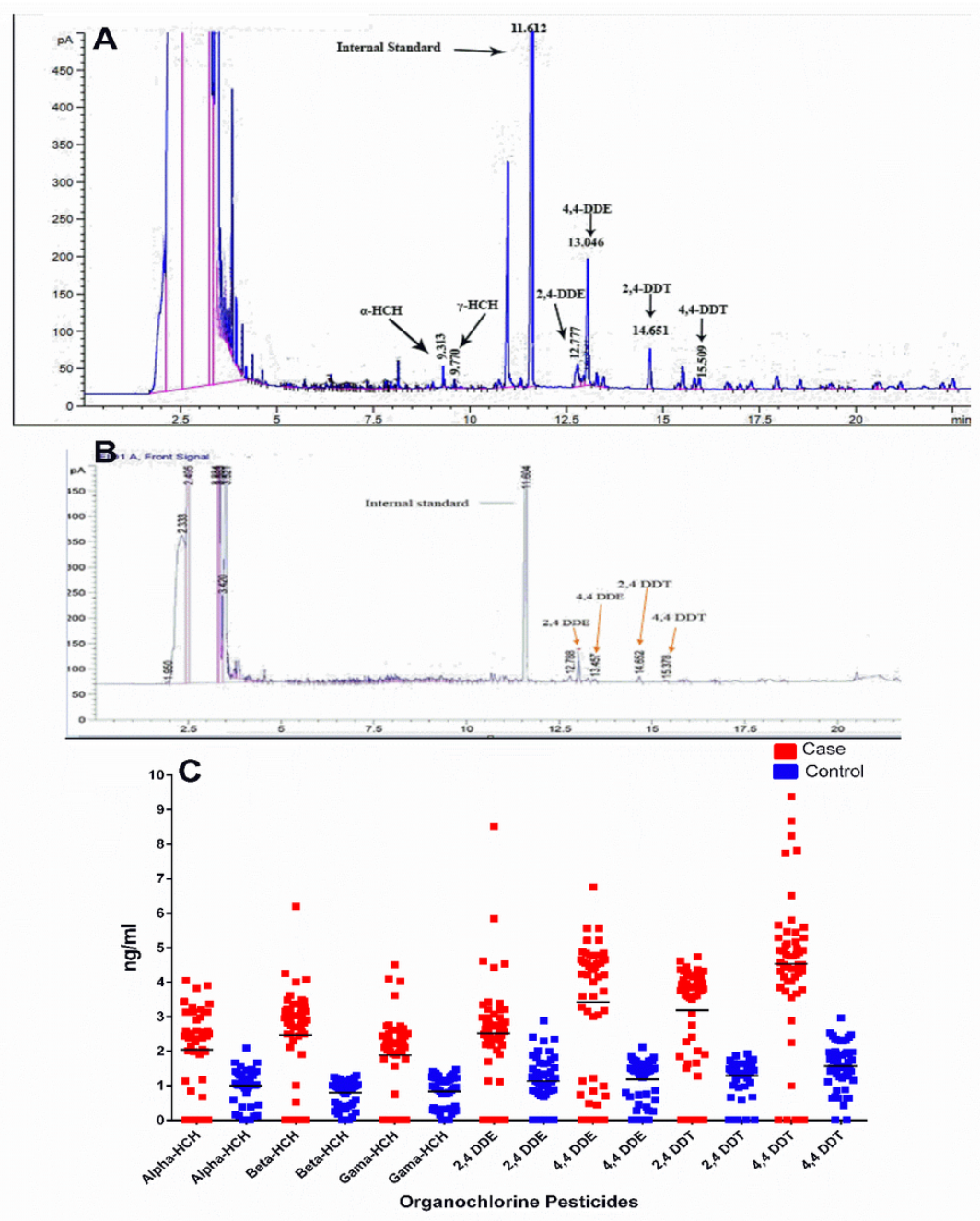

\section{Figure 2}

(a) Chromatogram curve sample of OCPs in lung cancer patient based on retention time. (b) Chromatogram curve sample of OCPs in healthy individual based on retention time. (c) A scatter chart gives information about serum levels of OCPs in lung cancer compared to the control group. The levels of a-, $\beta$ - and $\gamma$ $\mathrm{HCH}, 2,4-\mathrm{DDE}, 4,4-\mathrm{DDE}, 2,4-\mathrm{DDT}$, and 4,4-DDT were significantly higher in the lung cancer group as compared to the control group. 
(a)

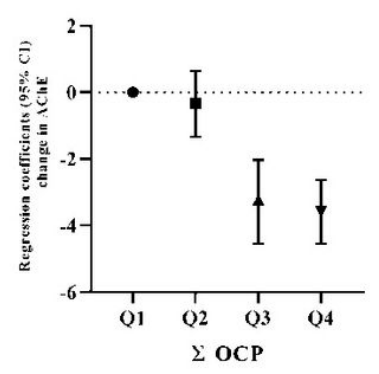

(d)

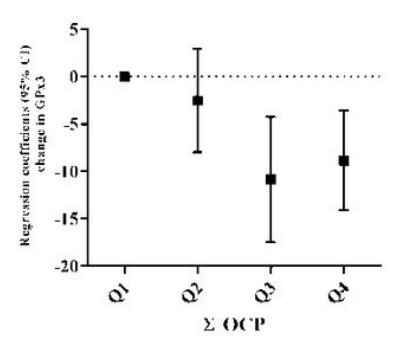

(g)

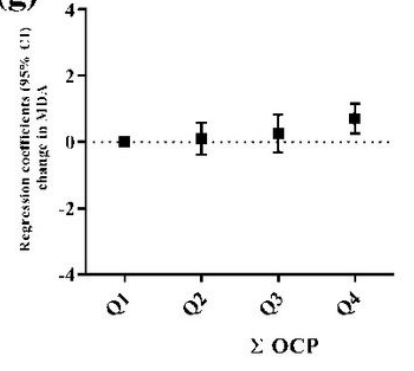

(b)

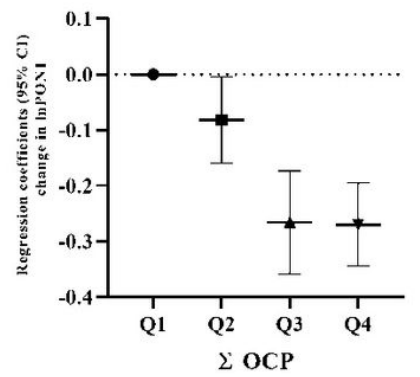

(e)

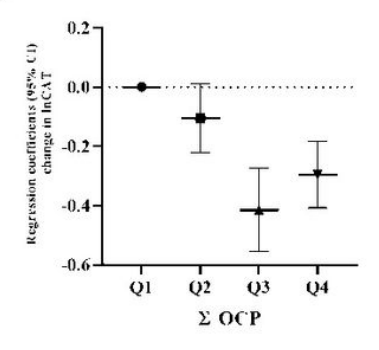

(h)

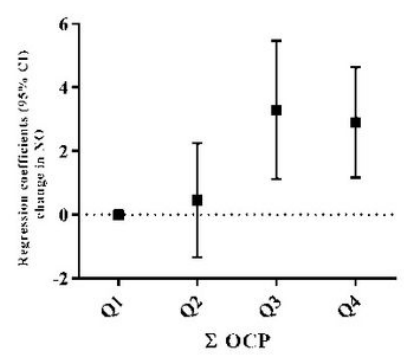

(c)

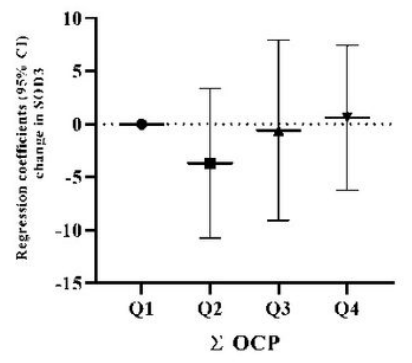

(f)

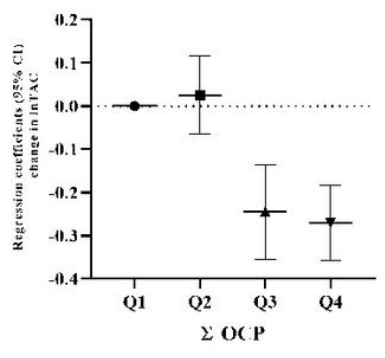

(i)

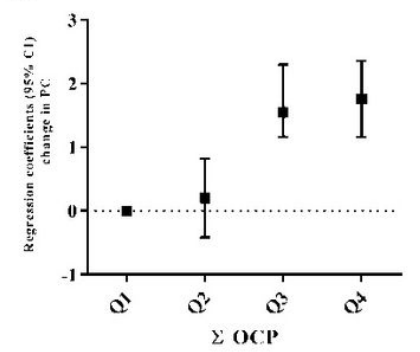

\section{Figure 3}

Adjusted regression coefficients ( $\beta$ [95\% confidence interval]) for a change in OS parameters associated with increasing quartiles of $\sum$ OCP in lung cancer. (a) There was in 3rd, and 4th quartile a significant decrease of AChE (b) InPON1 had a significant decrease in the 3rd and 4th quartile (c) SOD3 had no a significant difference when compared to the baseline (d) GPx3 had a significant decrease in the 3rd and 4th quartile (e) InCAT had a significant decrease in the 3rd and 4th quartile (f) InTAC had a significant decrease in the 3rd and 4th quartile (g) No significant difference was observed for MDA (h) There was in the 3rd and 4th quartile a significant increase of NO (i) PC had a significant increase in the 3rd and 4th quartile.

AChE: Acetylcholinesterase; PON1: Paraoxonase1; MDA: Malondialdehyde; SOD3: Superoxide dismutase3; GPx3: Glutathione peroxidase; CAT: Catalase; TAC: Total antioxidant capacity. NO: Nitric oxide; PC: Protein carbonyl. 